\title{
Hidden Costs of Multiple-Dose Products: Quantifying Ipratropium Inhaler Wastage in the Hospital Setting
}

\author{
Elissa S Y Aeng, Kaitlin C McDougal, Emily M Allegretto-Smith, and Aaron M Tejani
}

Can J Hosp Pharm. 2021;74(2):117-21

\begin{abstract}
Background: Previous studies have quantified wastage involving drugs that are available in multiple-dose formats. Ipratropium bromide by metered dose inhaler (MDI) is commonly used in hospitals, and may be contributing to waste of pharmaceutical and financial resources.

Objectives: The primary objective was to quantify the number of patients in the authors' health authority with waste of at least 1 ipratropium MDI. Secondary outcomes were the total number of wasted inhalers, the total number of wasted doses, the cost of wasted inhalers, the cost of wasted doses, and possible factors or explanations for inhaler wastage.
\end{abstract}

Methods: A retrospective chart review was conducted for patients with an order for ipratropium by MDI in 2019 at one of the acute care sites within the health authority (predefined sample size 336). The number of inhalers dispensed was compared with doses received to determine the number of inhalers wasted. Each patient's electronic chart was audited for possible factors and explanations for wasting of inhalers.

Results: Of the 336 patients, 79 (24\%) had wastage of at least 1 inhaler. In total, 34\% (98/290) of all inhalers dispensed and 87\% (50 693/58 000) of all doses dispensed were wasted. The total cost of wasted inhalers for the sample population was $\$ 2156$. The most common reason for inhaler wastage was no doses being administered after an inhaler was dispensed; the second most common reason was dispensing of an extra inhaler associated with a change in directions for use.

Conclusions: The use of multiple-dose MDI products in hospitals can lead to wastage of drugs and financial resources. Procedures need to be implemented to aid pharmacy and nursing staff in ensuring the most efficient use of these products. Evaluations of pilot methods to mitigate this waste are encouraged.

Keywords: drug waste, health expenditures, ipratropium, metered dose inhalers, multidose products

\section{RÉSUMÉ}

Contexte : Des études antérieures ont quantifié le gaspillage de médicaments disponibles dans des formats multidoses. Le bromure d'ipratropium administré par inhalateur-doseur (ID) est communément utilisé dans les hôpitaux et pourrait entrainer un gaspillage des ressources pharmaceutiques et financières.

Objectifs : L'objectif principal consistait à quantifier le nombre de patients relevant de l'autorité sanitaire des auteurs, qui étaient source d'un gaspillage d'au moins un ID d'ipratropium. Les résultats secondaires visaient à déterminer le nombre total d'inhalateurs et de doses gaspillés, le coût associé au gaspillage des uns et des autres, ainsi que les facteurs pouvant expliquer cette situation.

Méthodes : Les dossiers des patients ayant reçu une prescription d'ipratropium administrée par ID en 2019 dans l'un des sites de soins intensifs de l'autorité sanitaire ont fait l'objet d'un examen rétrospectif (taille de l'échantillon prédéfinie : 336). Une comparaison entre le nombre d'inhalateurs distribués et les doses reçues a permis de déterminer le nombre d'inhalateurs gaspillés. La vérification de chaque dossier électronique des patients a révélé les facteurs et les explications possibles du gaspillage des inhalateurs.

Résultats : Sur les 336 patients, on a noté un gaspillage d'au moins un inhalateur tous les 79 patients ( $24 \%$ ). Au total, le gaspillage se montait à $34 \%(98 / 290)$ de tous les inhalateurs distribués et à $87 \%$ (50 693/58 000) de toutes les doses distribuées. Le coût total des inhalateurs distribués à l'échantillon de population se montait à 2156 \$. La raison du gaspillage la plus fréquente était l'absence de doses administrées après la distribution d'un inhalateur; la deuxième raison concernait la distribution d'un inhalateur supplémentaire associée à une modification des instructions relatives à son utilisation.

Conclusions : L'utilisation de produits ID multidoses dans les hôpitaux peut entraîner un gaspillage de médicaments et de ressources financières. Des procédures doivent être mises en place pour aider les membres du personnel des pharmacies et le personnel infirmier à utiliser plus efficacement ces produits. II serait indiqué de procéder à des évaluations de méthodes pilotes pour atténuer ce gaspillage.

Mots-clés : gaspillage des médicaments, dépenses de santé, ipratropium, inhalateur-doseur, produits 


\section{INTRODUCTION}

Ipratropium bromide is a short-acting muscarinic antagonist indicated for treatment of acute asthma exacerbations and management of chronic obstructive pulmonary disease. ${ }^{1,2}$ In our health authority in British Columbia, Canada, ipratropium is available on formulary in the form of metered dose inhalers (MDIs) and nebules.

In the 2018/19 fiscal year (April 2018 to March 2019), ipratropium MDIs represented the second-highest inhaler expenditure for this health authority. MDIs are unique in that they are available only in multiple-dose formats; in Canada, the ipratropium MDI is supplied as a 200-dose canister. ${ }^{2}$ The nature of multiple-dose containers contributes to ipratropium wastage, because a full inhaler must be dispensed even if a patient requires only 1 dose during the hospital stay.

During drug shortages, wastage of medication may exacerbate the situation. The conservation of medications is especially important during pandemics, when there may be interruptions in international trading channels and increased demand for supportive and therapeutic agents used to treat the disease underlying the pandemic. ${ }^{3}$

Previously, Berwick and Hackbarth ${ }^{4}$ proposed that reducing waste would be an enormous opportunity to reduce health care costs. Ipratropium has the potential for greater wastage than occurs with other inhalers because this drug may be used on an as-needed basis, in addition to regularly scheduled use. Quantifying the amount of ipratropium inhaler waste and possible factors or explanations for the waste may suggest ways to reduce health care costs. ${ }^{3}$ Our primary objective was to determine the total number of patients for whom an ipratropium MDI was dispensed and subsequently wasted at acute care sites within our health authority.

\section{METHODS}

A retrospective chart review was conducted within 11 acute care sites in Fraser Health Authority. All patients with an order for ipratropium inhaler between January 1, 2019, and December 31, 2019, were eligible for inclusion in the review. Patients were identified through the pharmacy's electronic record, which documents inhalers sent from the dispensary and inhalers removed from automated dispensing cabinets located on the wards. For each patient identified in this way, the account number was then used to pull the corresponding scanned patient chart. The Fraser Health Research Ethics Board deemed this quality improvement review to be exempt from ethics approval, and written informed consent was not required.

To determine the total number of patients with wastage of at least 1 ipratropium inhaler, we considered an inhaler to have been "wasted" if any of the following occurred: the patient did not use an ipratropium inhaler that was dispensed for them at any point during the hospital stay, an extra ipratropium inhaler was dispensed when previously dispensed inhalers contained an adequate supply of the doses that the patient would need during the hospital stay, or an ipratropium inhaler was dispensed for a patient even though the patient did not have an order for this form of therapy. Secondary outcomes were the total number of wasted inhalers, the total number of wasted doses, the cost of wasted inhalers, the cost of wasted doses, and possible factors or explanations for inhaler waste. To determine the number of inhalers and doses that were wasted for each patient, we compared the number of doses (puffs) that the patient received, as documented in the medication administration record (MAR), with the number of inhalers and doses dispensed for that patient. The costs of wasted inhalers and doses were based on the price of an ipratropium inhaler in community pharmacies in British Columbia. We used community pharmacy pricing because our health authority's contract pricing is considered confidential. For each inhaler that was wasted, 1 contributing factor or reason for waste was assigned. The factors or reasons were determined in a systematic, step-wise manner, with explicitly documented reasons (i.e., documented loss, no ipratropium order, no doses administered) taking precedent over factors related to the timing of inhaler removal from an automatic dispensing cabinet or dispensing of an inhaler from pharmacy.

In 2019, a total of 12810 patients received an ipratropium inhaler at one of the acute sites in our health authority. Our group previously examined wastage of fluticasone propionate/salmeterol combination MDIs and dry powder inhalers and found that $19.6 \%$ of patients had an extra inhaler dispensed (i.e., "wasted"). ${ }^{5}$ Assuming that the effect size would be similar in the context of ipratropium inhaler wastage, a sample size of 333 patient charts was obtained, to yield a $98 \%$ confidence level and a $5 \%$ margin of error. A random number sequence generator was used to sample charts in a proportional manner with respect to the volume of patients seen at each hospital site. Because of rounding due to the representative chart sample, the final sample size was 336 patients. The primary and secondary outcomes were assessed using descriptive statistics.

Two investigators (K.C.M. and E.M.A.S.) independently extracted data from the patients' charts. For the first 10 charts, duplicate data extraction was performed, and the data were then assessed for appropriate extraction by a third investigator (E.S.Y.A.). Assessment for valid data extraction was also repeated for 5 charts one-third and two-thirds through the data collection process. Any discrepancies or ambiguities in the data were discussed, agreed upon, and resolved.

Data were extracted from the pharmacy electronic record and patient charts. Variables collected included the hospital site, the patient's account number, the number of inhalers dispensed, the number of inhalers removed from an automated dispensing cabinet, the total number of doses the patient received, and any probable reasons for inhaler 
wastage if such wastage occurred. Patient characteristics were also recorded, including admission status, number of bed/ward transfers, intubation during visit, and past or current history of chronic respiratory disease, such as asthma or chronic obstructive pulmonary disease. All data containing patient identifiers were stored on a protected drive, and patients were assigned a coded study number. The data were analyzed using descriptive statistics.

\section{RESULTS}

A total of 336 patient charts were reviewed. Most patients (284 [85\%]) were admitted to hospital (as opposed to having a short emergency department visit), and 263 (78\%) had at least 1 bed or ward transfer (Table 1). Past or current history of a chronic respiratory disorder was reported for 247 (74\%) of the patients (Table 1).
The number of patients in our health authority for whom at least 1 ipratropium inhaler was dispensed unnecessarily was 79 (24\%; range $9 \%$ to $80 \%$ at individual sites). Of the 290 ipratropium inhalers dispensed, 98 (34\%) were wasted. The highest number of inhalers wasted during a patient's hospital stay was 5 inhalers ( $n=1$ patient). A total of 58000 doses were dispensed, and 50693 (87\%) of these doses were wasted. For our cohort of 336 patients, the total cost of wasted inhalers was $\$ 2156.00$, and the total cost of wasted doses was $\$ 5576.23$.

The most common reason (33\%) for inhaler wastage was dispensing of an inhaler from which no doses were administered to the patient (Table 2). In this situation, the inhaler was dispensed for use on an as-needed or regular basis, but there was no record in the MAR of any doses being given. The second most common reason (18\%) originated from pharmacy dispensing an extra inhaler in association

\section{TABLE 1. Patient Characteristics}

\begin{tabular}{|c|c|c|}
\hline Characteristic & & 36) \\
\hline Admitted to hospital & 284 & (85) \\
\hline Transferred bed or ward during hospital stay & 263 & (78) \\
\hline Past or current history of chronic respiratory disease $\mathrm{a}^{\mathrm{a}}$ & 247 & (74) \\
\hline Chronic obstructive pulmonary disease & 169 & $(50)^{a}$ \\
\hline Asthma & 64 & $(19)^{\mathrm{a}}$ \\
\hline Other diagnosis & 81 & $(24)^{a}$ \\
\hline Intubation during hospital stay & 71 & (21) \\
\hline At least 1 inhaler removed from automated dispensing cabinet & 107 & $(32)$ \\
\hline
\end{tabular}

aPercentages do not sum to $74 \%$ (the total of those with chronic respiratory disease), because some patients had multiple respiratory comorbidities.

TABLE 2. Factors Contributing to Wastage of Inhalers

Factor

Inhaler dispensed, but no doses administered to patient

Pharmacy dispensed extra inhaler when there was an order to change directions for use, even though patient's first inhaler had sufficient number of doses to accommodate the altered directions

Inhaler dispensed even though patient had no order for this form of therapy

Inhaler did not follow patient on transfer

Removal of a second inhaler from automated dispensing cabinet within $24 \mathrm{~h}$ of removal of a first inhaler

Loss of inhaler documented in chart note or medication administration record

Nursing provided extra inhaler from automated dispensing cabinet when there was an order to change directions for use, even though patient's first inhaler should have had sufficient number of doses to accommodate the altered directions

Unable to determine

apercentages do not sum to $100 \%$ because of rounding
No. $(\%)$ of Wasted Inhalers ${ }^{\mathrm{a}}$ $(n=98)$

$32 \quad$ (33)

$18 \quad(18)$

$15 \quad(15)$

14 (14)

4 (4)

$1 \quad(1)$

1 (1)

13 
with a change in directions for use, even though the patient's current inhaler still contained a sufficient number of doses to accommodate the modified administration. Similarly, in 1 instance, an inhaler was wasted because nursing staff provided the extra inhaler from an automated dispensing cabinet after an order was written to change the directions for use. There was only 1 instance in which the wastage or loss of an inhaler was explicitly documented on the MAR as "not available" and "pharmacy [was] called."

\section{DISCUSSION}

This retrospective chart review quantified the magnitude of waste of ipratropium MDIs within our health authority, showing that for $24 \%$ of patients who received ipratropium inhalers, at least 1 inhaler was wasted. This is similar to the findings in a previous study of wastage of fluticasone/salmeterol inhalers, in which $19.6 \%$ of patients had a wasted inhaler. ${ }^{5}$

When the total cost of wasted inhalers in the sample population was extrapolated to all 12810 patients with an ipratropium order in 2019, we calculated more than $\$ 82000$ in excess drug spending. Additionally, when the cost of wasted doses was extrapolated to all patients who received ipratropium in this health authority in 2019, we estimated that wastage could represent over $\$ 212000$. Retail pricing is typically higher than contract pricing for the health authority, so these calculations may overestimate the true budget implications for the hospital setting. Nonetheless, the actual implications are likely to be substantial enough to warrant the same level of concern, especially given that health authorities are publicly funded.

The dispensing of an inhaler without the patient receiving any doses was the most common reason for wastage, accounting for $33 \%$ of all inhalers wasted. In these instances, no doses were recorded on the MAR, which suggests that the patient either did not require any doses or was discharged before doses were required. In this situation, we assumed that dispensed inhalers were not returned to stock or used by another patient. To help mitigate waste secondary to this reason, dispensing of as-needed ipratropium orders could be delayed for patients who do not present with an acute respiratory condition. Alternatively, inhalers in ward stock could be dispensed in sealed bags, to ensure drug integrity and allow subsequent re-dispensing if the seal is not broken.

The second most common reason for wastage of inhalers in our chart review was dispensing of a new inhaler when there was a change in the ipratropium order, even though the patient's first inhaler had doses remaining, according to the doses recorded on the MAR. In this situation, instead of checking whether an inhaler had already been dispensed, the pharmacy automatically dispensed a new inhaler. Staff education is required to address this factor. One suggestion for improvement is to increase awareness among pharmacy and nursing staff of the potential for this form of waste and to encourage staff to use the patient's previously dispensed inhalers with doses remaining.

Waste assessment is particularly important for drugs dispensed in multiple-dose formats, which have a greater potential for waste than their single-dose counterparts. For example, a patient who has a prescription for the manufacturer's recommended dose of ipratropium ( 2 puffs given 4 times daily ${ }^{1,2}$ ) and the average length of hospital stay $\left(7\right.$ days $\left.^{6}\right)$ would use about 60 puffs of ipratropium. In our health authority, after the patient is discharged, the remaining 140 puffs in the canister would not be shared with another patient, and the canister would be discarded. In contrast, single-dose formulations, such as tablets, are prepared in unit-dose packaging and are typically dispensed daily or with, at most, a few days' supply.

Minimizing the cost of wasted doses is a complex issue. The ideal solution would be for manufacturers to produce inhalers with fewer doses or for hospitals to adjust their policies to allow certain patients to take their inhalers home after discharge. Another possibility would be to use the patient's own supply of multidose inhalers, which has previously been shown to result in cost savings. ${ }^{7}$ In times of tremendous drug shortage, exploring the possibility of cleaning and recycling partially used inhalers might be another option. ${ }^{8}$ Should a common canister program be implemented, protocols would be needed to minimize the risk of infection. ${ }^{8}$

Our evaluation had several limitations related to the nature of retrospective chart reviews. Four of the hospitals included in the analysis did not have automated dispensing cabinets, which meant that removals of inhalers from ward stock could not be tracked electronically. This might have resulted in an underestimation of inhaler waste, given that any inhalers removed from ward stock at those hospitals could not have been quantified unless their removal was explicitly documented (hand-written) in the chart. In addition, ipratropium MDIs require priming before the first use, which involves the purposeful wasting of the first 2 actuations. ${ }^{2}$ We did not account for these priming puffs, because priming of inhalers is not normally documented in the patient chart and thus we could not be sure how often each inhaler was primed. Not accounting for priming doses may have led to overestimation of waste; however, the number of priming puffs is minimal relative to the total number of puffs in a canister, and is unlikely to have affected our primary outcome. In some cases, no inhaler was billed (i.e., there was no electronic record of dispensing) even though a patient was documented to have received doses. This situation could have led to underestimation of inhaler waste. Finally, in some cases it was challenging to determine the reason for inhaler wastage, and ultimately we were unable to determine the reason in 13 cases. Additionally, we did not evaluate clinical need (or lack thereof) as a potential reason for inhaler wastage. Patients who received ipratropium without a valid clinical indication may have further contributed to inhaler waste. 
Notably, our study did not take into consideration the potential costs associated with time spent by pharmacy and nursing staff in finding lost inhalers or increasing communication among staff. It is possible that procedural changes to address the problems outlined here could increase staff workload, resulting in additional costs that might outweigh the savings achieved by reducing inhaler waste. We would encourage the testing and evaluation of a variety of methods and policies to decrease pharmaceutical waste and the spending associated with multiple-dose inhaler products.

\section{CONCLUSION}

This retrospective chart review highlighted significant waste of pharmaceutical and financial resources related to ipratropium MDI inhalers. These results represent compelling support for more organized and consolidated drug distribution in hospitals. To help mitigate waste, health care institutions should consider stricter protocols related to inhaler dispensing, and all hospital staff should be made aware of the waste occurring with multiple-dose format drugs, such as MDIs. In addition, effective communication between pharmacy and nursing staff should be promoted to help ensure that medications are not dispensed unnecessarily.

\section{References}

1. Ipratropium (oral inhalation) [product monograph]. In: Lexicomp online [database on internet]. Lexi-Comp; [cited 2020 Jan 15]. Available from: https://online.lexi.com/. Subscription required to access content.

2. Atrovent HFA (ipratropium bromide) [product monograph]. Boehringer Ingelheim; 2019 Nov 4 [cited 2020 Jan 15]. Available from: https://www.boehringer-ingelheim.ca/sites/ca/files/atroventpmen.pdf

3. Badreldin HA, Atallah B. Global drug shortages due to COVID-19: impact on patient care and mitigation strategies. Res Social Adm Pharm. 2021;17(1):1946-9.
4. Berwick DM, Hackbarth AD. Eliminating waste in US health care JAMA. 2012;307(14):1513-6.

5. Aeng ESY, Dhaliwal MM, Tejani AM. A cautionary tale of multipledose drug products: fluticasone and salmeterol combination inhaler waste. J Eval Clin Pract. 2020;26(6):1699-702.

6. DAB/HMDB inpatient hospitalizations: volumes, length of stay, and standardized rates. Canadian Institute for Health Information; 2019 [cited 2020 Feb 21]. Available from: https://www.cihi.ca/en/dadhmdb -inpatient-hospitalizations-volumes-length-of-stay-and-standardized -rates

7. Wong GYC. Cost impact of using patients' own multidose medications in hospital. Can J Hosp Pharm. 2014;67(1):9-16.

8. Larson T, Gudavalli R, Prater D, Sutton S. Critical analysis of common canister programs: a review of cross-functional considerations and health system economics. Curr Med Res Opin. 2015;31(4):853-60.

Elissa S Y Aeng, BSc(Pharm), ACPR, PharmD, is with the Pharmacy Department, Lower Mainland Pharmacy Services, Surrey, British Columbia. Kaitlin C McDougal, PharmD, is with the Pharmacy Department, Lower Mainland Pharmacy Services, Vancouver, British Columbia.

Emily M Allegretto-Smith, BSC, PharmD, is with the Faculty of Pharmaceutical Sciences, The University of British Columbia, Vancouver, British Columbia.

Aaron M Tejani, BSc(Pharm), PharmD, ACPR, is with the Therapeutics Initiative, The University of British Columbia, and the Pharmacy Department, Lower Mainland Pharmacy Services, Vancouver, British Columbia.

Competing interests: For activities outside the study reported here, Aaron Tejani has received financial, in-kind, and/or travel support from the Therapeutics Initiative (The University of British Columbia), Doctors of BC (guideline working group), British Columbia Division of Family Practice (continuing education events), and the BC Ministry of Health (presentation at research rounds). No other competing interests were declared.

\section{Address correspondence to:}

Dr Elissa S Y Aeng

Pharmacy Department

Lower Mainland Pharmacy Services

13750 96th Avenue

Surrey BC V3V $1 Z 2$

email: elissa.aeng@fraserhealth.ca

Funding: None received. 